\title{
DipSW students' satisfaction with practice teaching on their first placement
}

\section{Campbell Killick ${ }^{1}$}

Summary: This research report explores the influence of specific elements of the practice teaching role on students' experience of placement learning. The findings provide a valuable insight at a time when placement learning is being reviewed.

The entire population of first placement students in Northern Ireland (approximately 240) was surveyed using a short questionnaire. 149 Questionnaires were returned providing a response rate of $62.5 \%$.

Students did not indicate any strong preference for long-arm or singleton practice teaching identifying strengths and weaknesses specific to each model. There was some evidence that these two models provide distinctly different forms of placement learning. Students seemed to value well organised support groups but attitudes to group supervision were mixed. Supervision style seemed to be influenced by practice teacher gender and model of supervision.

The practice teacher/ student gender mix and the age and experience of the student were found to influence the placement experience.

Key words: practice learning, supervision style, student support, group supervision, student perspectives, research

\section{Research \& Development Officer}

Address for Correspondence: Social Services Training, The Clock Tower, Downshire Hospital, Ardglass Road, Downpatrick, BT30 6RA.

Campbell_killick@dltrust.n-i.nhs.uk 


\section{Introduction}

Social work training is currently undergoing an extensive review that will radically change the way in which social workers are educated. A crucial aspect in the design of the proposed three year degree level course will be the balance between college-based learning and 'practice learning'. Although some new and innovative approaches are being suggested including the simulation of practice learning (Valios, 2002; Miller, 2002; Dick, Headrick \& Scott, 2002), commentators generally agree that placement learning will be at the forefront of any curriculum, and the practice teacher will be a central figure within these placements.

Traditionally the practice teacher worked at the placement site, combining the role of practitioner and supervisor, and in Northern Ireland, the majority of practice teachers use this 'singleton' model. In contrast the long-arm practice teacher may supervise a number of students at separate locations assisted by 'on-site supervisors'.

The vast majority of student supervision by practice teachers is provided in weekly one-to-one meetings, although some practice teachers do supervise, enable, teach and assess groups of students together.

The practice teacher's style of interaction with students is often very individualistic. Glenda Short (2002) makes use of Munson's (1993) definition of supervision style that includes patterns of communication, focus and theoretical orientations to supervision.

This study focuses on a small number of factors relating to practice teaching that may impact on the student's practice placement experience. However, the importance of other factors should not be overlooked. The student is obviously a key player in influencing their own placement experience and their maturity, academic background and experience are important. Line managers/on site supervisors and college tutors have an active part in the 'training team' that supports the placement. The quality of the placement site is crucial and work pressures, staff changes and internal politics can detract from an agency's student focus. Students are placed in a range of settings and in some placements students can struggle to identify a social work role.

The demand for placements is increasing and the crisis in identifying quality placements is well documented both locally (Wilson 2001) and nationally (Green, 2000), although it should be noted that pressures are markedly greater in England than in Northern Ireland. Bernard Moss

40 Journal of Practice Teaching 6(1) 2005, pp.39-56

(C) 2005 Whiting and Birch 
(1999) describes how in this climate 'necessity becomes the mother of invention'. Agencies have adopted a range of strategies including long-arm and group supervision to meet their placement learning commitments. However research on the quality of these new strategies is limited.

This study considers those practice teacher factors that could be influenced by the training provider or by the practice teachers themselves. Other secondary practice teacher variables like age and gender will be included so that possible relationships can be tested. These are obviously outside the control of individual practice teachers but could be influenced if training providers wished to 'match' students and practice teachers to establish effective partnerships.

In collating student feedback on practice teaching in Northern Ireland this study will provide a valuable insight for practice teachers, planners and course providers. It will also inform the discussion on the future provision of practice learning.

\section{Literature review}

\section{The Model of Practice Teaching}

It is possible to identify within the literature a range of approaches that might constitute models of practice teaching. This study seeks to compare 'long-arm' and 'singleton' models, discussing the implications that these arrangements might have on the student's placement experience. It is important to recognise that the influence of the model is far greater than the practical arrangements. In the long-arm model the supervision role is shared between the practice teacher and the on-site supervisor. As a result, the student has a larger group of professionals directly involved in their practice learning and they often spend more time in formal supervision. This complex supervisory relationship can bring both strengths and weaknesses to the long-arm model.

Gillian Bridge (1999) describes the real danger of confusion resulting from the complex approach to supervision if all parties are not entirely clear of the distinct roles. Without clear guidelines the student may receive 'mixed messages', raising their anxiety and reducing their potential learning. Bridge also outlines the practical difficulty when a

41 Journal of Practice Teaching 6(1) 2005, pp.39-56

(๑) 2005 Whiting and Birch 
practice teacher is not a member of the team where the student is placed. They are not beside the student as they progress through placement but rather facilitate learning from a distance, 'dropping in' to supervise, assess and teach, based on samples of the student's work. Singleton practice teachers tend to use more of an apprenticeship approach (Doel et al, 1996), working closely with students to model good practice.

\section{The method of practice teaching}

The use of group supervision or group support is an attempt to encourage 'cross fertilisation' allowing students to learn from the experience of others. Shafer (1982) highlights the value of this approach:

The advantage of this method is the richness provided by peer learning. The presentation of case material to the group by each student multiplies the experience for all. The group may become a source of support for each student as well as an arena for testing ideas. (p.222)

McVicker and Bamford (1999) suggest that group supervision methods allow the practice teacher to observe the student within the group process. A range of group activities could be used to facilitate learning including role-plays, group discussions and simulations. More recently specific group activities like problem solving and action learning have been developed to formalise the group process. A clear distinction should be drawn between group supervision and student support. In group supervision the practice teacher can assess the students as well as facilitating the group. Student support groups tend to be a student led forum for general support and discussion.

Brown and Bourne (1996) and McVicker and Bamford (1999) stress that the role of group supervisor requires specific skills and knowledge if the method is to be used effectively. The approach requires commitment from the supervisor and the students and it may not be appropriate for all students or all settings. 


\section{The style of practice teaching}

During recent years there has been increasing research interest in the supervision styles used within social work education and other fields. It should be noted that these do not generally focus on practice teaching but they do assist in the understanding of the types of supervision styles and their impact on the supervisee. Many of the studies build upon the work in the USA by Rosenblatt and Mayer (1975) who surveyed 233 students and found that 50 were dissatisfied with the practice teaching that they received. From the students' descriptions Rosenblatt and Mayer identified the following four 'objectionable supervisory styles':

- Constrictive: Overly directive;

- Amorphous: Lacking focus or direction;

- Unsupportive: Aloof, cold, critical or hostile;

- Therapeutic: Focusing on the student's deficiencies.

Further studies carries out in the USA investigated the link between supervision style and student satisfaction. Fortune et al (1985) measured student's perceptions of whether the instructor enjoyed teaching and encouraged ideas. The authors were not surprised when this factor was shown to have the strongest correlation to students' satisfaction with supervision, but it should be noted that the link between time spent in supervision and satisfaction was much weaker. Fortune et al concluded that quality of supervision was more important to students than quantity. Studies by Fernandez (1998) and Raskin (1982) identified helpful approaches to supervision and discussed the factors that students found supportive. Kadushin (1976) lists 20 characteristics of the 'good' supervisor and sums them up with the maxim 'Good supervisors are available, accessible, affable and able' (p.339).

It should be recognised that this study seeks to establish practice teachers' supervisory styles as perceived by their students. It cannot be presumed that practice teachers would score their style of supervision in a similar manner. The work of Collins et al (1992) showed that practice teachers and students differed significantly in rating key elements of the supervision relationship. This certainly does not render the resulting data invalid but care will be required in interpreting the results.

Friedlander and Ward (1984) produced a 'supervisory styles inventory' (SSI) that identifies three factors relating to supervision 
style. They tested the supervisory styles inventory in a range of settings to show that the scales 'demonstrated robust reliability and construct validity' (p 541).

The supervisory styles inventory defines the following dimensions:

- Attractiveness: A collegial approach (e.g. warm, supportive, friendly open, flexible).

- Interpersonally Sensitive: A relationship oriented approach (e.g. invested, committed, therapeutic, perceptive.

- Task Orientated: A content focused style (e.g. goal orientated, thorough, focused, practical, structured).

\section{Other factors}

Some writers have suggested other factors relating to a practice teacher's background or identity that may influence practice learning. Discussing the impact of race, Idris Stokes (1996) stresses

the need to have people from diverse backgrounds in social work education, practice and training. (p.15)

It has been generally accepted that there are disproportionately few black practice teachers. All of the students in Bridge's (1999) study were black but they emphasised expertise and sensitivity rather than racial background. Bridge highlights the similarities with the findings of Marsh and Treseliotis (1996), who did note that some black students valued contact with a black 'mentor' if their supervisor was not black.

Less has been written about the significance of difference in the areas of gender, age, sexual identity or religious identity. In each there is the potential for a practice teacher to discriminate either consciously or unconsciously. It might be presumed that as with race, a practice teacher's sensitivity to the student's needs is more significant than their own background or identity. 


\section{Research design and methods}

Students in Northern Ireland can study social work on one of four settings that include undergraduate, graduate and post graduate courses. Each course requires students to participate in placement and college based learning. This study aimed to establish the views of all social work students in Northern Ireland who have just completed their first practice placement. Students were surveyed at the end of placements in their college groups so that their experience would still be fresh in their minds. Only first placement students were selected, as there is evidence that students may have different perceptions of the supervision in first and second placements (Fernandez, 1998).

The questionnaire focused primarily on the three variables within practice teaching that have been discussed above: model, method and style. It also sought to measure students' satisfaction with practice teaching and with placement learning. Some secondary variables such as age and gender were included but these were limited so as not to divert the respondents' attention and the subsequent analysis away from the core focus of the study.

The questionnaire was composed of numeric scales with sections for students to add comments. Friedlander and Ward's 'Supervisory Styles Inventory' (SSI) (1984) provided an appropriate empirical measure that has been cross-validated with trainees being supervised in the fields of psychology, psychiatry and social work. Student satisfaction was measured with a series of Likert scales used in previous studies (Vonk et al 1996).

\section{Findings}

Of the questionnaires 149 were returned, representing $62 \%$ of the target population estimated at 240 . In considering these factors it should be recognised that some practice teachers supervise more than one student. For this reason, the findings do not provide a description of 149 practice teachers but rather the experiences of 149 students.

Student's age and level of experience proved to have an impact on placement experience. Younger students were less likely to understand the practice teachers role 'very well'. They perceived their practice

45 Journal of Practice Teaching 6(1) 2005, pp.39-56 @ 2005 Whiting and Birch


teachers supervision style differently than their older and more experienced counterparts. A disproportionate number of failing students were young or inexperienced.

No clear preference for practice teacher gender was indicated although mean satisfaction was slightly higher in different gender combinations. Similarly, students tended to give a higher rating on the attractive scale to practice teachers of a different gender. This study provided some evidence that male and female practice teachers may differ in their approach to supervision. Male practice teachers tended to provide less frequent supervision and shorter supervision sessions. In this study, students with a male practice teacher were less likely to have a formal supervision agreement.

In general, students were more satisfied with more frequent supervision. The relationship between duration and satisfaction was more complex with students expressing dissatisfaction with both extremes.

Over $72 \%$ of the students received long-arm supervision (n=108). In this study, students do not indicate a clear preference for long-arm or singleton practice teaching. Students reported marginally higher levels of overall satisfaction and contribution to practice learning for singleton supervision. They also reported marginally higher ratings of practice teacher competence for long-arm practice teachers although this was not statistically significant.

All of the failing students had long arm placements. The limited numbers of returns $(n=4)$ prevent further analysis of this relationship, which would benefit from more in depth investigation.

The analysis of data relating to group support and supervision proved to be complex as students interpreted these concepts in a number of different ways. The frequency of support groups varied widely as did their content and facilitation. The three satisfaction ratings increase with frequency of support groups. However, satisfaction drops with $6+$ support groups. These relationships are not statistically significant Quantitative data is supported by the students' comments. The majority $(n=20)$ of those who commented on support groups found them helpful, although 3 students found groups that included students from various stages and programmes unhelpful.

Some form of group supervision was received by received by $22 \%$ of students $(n=33)$ and $8 \%(n=12)$ of students had group supervision more than twice. Comments show both enthusiasm and concerns about 
the group supervision process.

The three supervision styles identified by Friedlander and Ward (1984) proved to be valid as they showed strong correlation with their individual items. Each of the styles correlated strongly with the three measures of satisfaction. However, the strongest correlation was between the attractive style and satisfaction with practice teaching. Interestingly, the styles showed different correlation across the three elements of satisfaction rating. The attractive style correlated most with satisfaction with practice teaching, while the interpersonal and task styles correlated most with contribution to placement learning.

It might be presumed that long-arm and singleton practice teachers adopted differing styles of supervision. In both cases the attractive style was by far the most prevalent. However, proportionally more long-arm practice teachers were categorised as being task oriented. Similarly, proportionally more singleton practice teachers were categorised as having the attractive style of supervision. Statistical testing shows that this is only a moderate relationship.

A more substantial relationship seems to exist between practice teachers' gender and supervision style. Female practice teachers seem to be more likely to be task oriented and male practice teachers seem to be more likely to have an 'attractive' supervision style.

It was not possible to consider the relationship between supervision style and placement outcome in any depth, as only four failing students returned a questionnaire. It is perhaps not surprising that none of the failing students identified their practice teacher as having an attractive supervision style. The majority of students' comments relating to supervision style were positive $(43 \%, \mathrm{n}=64)$. Comments frequently described supportive $(n=25)$ and relaxed $(n=12)$ styles as helpful.

The strongest single factor in determining students' satisfaction was the final outcome of placement. Some students' comments ( $n=9)$ focused on passing the placement, the portfolio and other assessed material. This could produce positive or negative perceptions. Other students' satisfaction related to their developing social work competence, although the learning process was not always comfortable. Some students $(n=7)$ described how their placement satisfaction was influenced by factors outside the practice teaching relationship. These included the nature of the placement, and the influence of the on-site supervisor or tutor.

47 Journal of Practice Teaching 6(1) 2005, pp.39-56 (C) 2005 Whiting and Birch 


\section{Analysis}

\section{Student Factors}

The evidence suggests that younger students experience placements and supervision differently from their older counterparts. Their tendency to rate practice teachers as more task orientated is in line with the findings of Friedlander and Ward. This may indicate that some younger students expect practice learning to resemble the didactic teaching of the classroom, while older students are more comfortable participating in adult learning approaches. Fernandez (1998) found that students with placement experience were less focused on the skills and abilities of the practice teacher. She suggested that this was because 'students experienced a degree of autonomy in handling practice tasks and expressing their views on work and learning' (p.182). In short, experienced students seem to take more responsibility for their own learning.

Although the data in not conclusive it is possible that some young and inexperienced students face difficulties that relate to their preferred learning style rather than their potential to be social workers. If this is the case, a developmental understanding of the students' needs similar to that discussed by Secker (1993) or Stoltenberg and Delworth (1987) may allow more effective supervision. This issue will become increasingly important as the new degree is likely to attract students who are more qualified but less experienced. Clearly students should take responsibility for their own development, but good practice teaching must be tailored to the student's needs. As student demographics change, practice teachers and placement providers will be required to reconsider how they provide equitable and effective practice learning opportunities.

\section{Practice teacher factors}

The gender ratio within this study (37\% male n 54, and 63\% female $\mathrm{n}=92$ ) broadly resembles that found by Wilson (1998). There was no evidence to support Vonk et al's findings that 'same-gender supervisorsupervisee combinations yielded higher student satisfaction' (p.416). In fact, both male and female students reported slightly higher satisfaction 
with different gender combinations. This does not disprove Vonk et al's assertion that gender can influence the supervision relationship. However it does suggest that the relationship is not a simple one. Vonk et al found that female students rated male practice teachers higher on the 'attractive' element of the Supervisory Styles Inventory and they interpreted this as relating to supervision style of males. The data from this study suggests that both male and female students give a higher 'attractive' score to supervisors of a different gender. Vonk et al point out that gender only accounts for a small part of overall satisfaction and they echo previous findings that intentional 'matching' of student to supervisor on the grounds of gender is not indicated.

\section{Frequency and duration of supervision}

The data shows that students distinguish between the frequency and duration of supervision. Generally, students were more satisfied with more frequent supervision, but the relationship between duration and satisfaction was more complex with students expressing dissatisfaction with both extremes. This is in line with Fortune's conclusion that quality of supervision was more important to students than quantity. It also suggests that prolonged infrequent supervision does not equate to brief frequent supervision. As each student has individual preferences and needs, the timing of supervision needs to be negotiated and reviewed throughout the placement.

\section{Practice teacher's role}

The evidence provided shows that responsibility for practice teaching is shifting away from operational staff towards training teams and independent teachers. 29\% of students described their practice teacher as a 'social worker' and this is significantly less than in other studies (e.g. Knight 1996). Of the 43 practice teachers with the role of 'social worker', 11 were participants on the practice teaching award course. The data shows that $82 \%$ of candidates on the practice teaching award were singleton practice teachers, while $7 \%$ of all placements used a long arm practice teacher. Despite the efforts of Trusts to identify and train singleton practice teachers, the role is increasingly being taken by

49 Journal of Practice Teaching 6(1) 2005, pp.39-56

(C) 2005 Whiting and Birch 
long arm specialists. This supports findings of Wilson (1998) and Rea (1996) who discussed the difficulties in retaining singleton practice teachers. Long arm practice teaching may be a valid model to supplement singleton provision, but it is concerning that in some areas it has begun to replace it.

It is possible that more second placements are supported by singleton practice teachers but this does not rectify the stark disparity in the two models of practice teaching.

Although the student's satisfaction does not change significantly with the model of practice teaching, a slight differential exists that seems to be supported by the qualitative data. Students perceive singleton practice teachers as having a more attractive style of supervision and providing greater overall satisfaction with placement. In a long arm placement, some of the supportive aspects of supervision are provided by the on-site supervisor, leaving the practice teacher to focus on the learning tasks. However, it should not be presumed that the student understands these mechanisms. A proportion of students under both models stated that they did not fully understand their practice teacher's role. Generally a clear understanding was closely related to satisfaction with placement. The findings are very similar to those of Karban (1999), and Lawson (1998) who stressed the importance of clearly defined roles and procedures in ensuring a good quality placement. In many cases, the students' experience related to the effectiveness of 'the triangular relationship between the student, the supervisor and the practice teacher' (Lawson, p.242).

All of the failing students had long arm placements. The limited numbers of returns prevent further analysis of this relationship, which would benefit from more in depth investigation.

Students' qualitative responses suggest that the two models have their own inherent strengths and weaknesses. Long arm practice teachers were less accessible but they provided ring-fenced time when learning could be discussed. Singleton practice teachers often had expertise in their area of practice but could be distracted by the pressures of work.

\section{Group support / group supervision}

The provision of group supervision and support proved to be variable in both quantity and quality. Students seemed to value support groups

50 Journal of Practice Teaching 6(1) 2005, pp.39-56

(C) 2005 Whiting and Birch 
DipSW students' satisfaction with practice teaching on their first placement

that were focused on their needs, although groups supporting a range of students were often deemed ineffective. Some agencies seemed to provide little in support for students outside the placement setting. Facilitating effective student support groups may not be easy but agencies should be encouraged to consider the support needs of their students.

Students' attitudes to group supervision were mixed and their concerns echoed the findings of McVicker and Bamford (1999) who identified potential drawbacks as well as benefits from the group supervision process. Comments from some students seem to indicate that the group supervision setting caused further anxiety and they felt less able to engage in the process. Group supervision can be highly effective when targeted at the needs of specific students. When used for the practice teacher's convenience they can often be counter- productive.

\section{Style of supervision}

Students seemed to be most satisfied with the attractive style of practice teaching, and characteristics like 'supportive' and 'flexible' were highly valued. This is in line with the findings of other writers (Short, 2002; Vonk, 1996). Unhelpful supervision styles identified by students relate to the approaches described by Rosenblatt and Mayer (1975) and Secker (1993). As Secker found, the most common unhelpful approach was the amorphous approach where supervision lacked focus or structure. None of the comments made by students related directly to the constrictive approach described by Rosenblatt and Mayer, but the experience of nine students closely resembled the unsupportive or therapeutic approaches.

The existence of unhelpful supervision styles and, in one case, poor practice, highlights the need for a system of monitoring practice teaching. Agencies and Trusts have a responsibility to ensure the quality of their placements and practice teachers.

In a number of cases, the students discussed positive or negative relationships between their practice teacher's style of supervision and their own learning style. This area has been studied in depth by Short (2002) in South Carolina. Further local research into these factors would be helpful.

51 Journal of Practice Teaching 6(1) 2005, pp.39-56 (C) 2005 Whiting and Birch 


\section{Satisfaction}

The students' comments on satisfaction indicate the complexity of placement learning. The strength of the pass/fail factor may have clouded the evaluation of other more subtle factors. The quality of practice teaching was central to the placement experience although the support of other staff was often significant. It is important to recognise that in practice it is not possible for other parties to compensate for failings on the part of the practice teacher, the on-site supervisor or the tutor.

\section{Conclusion}

The findings identify a number of key factors that combine to influence student satisfaction and the overall effectiveness of practice placements. As the demand for placement sites increases it essential that those with influence over the process are proactive in maximising the quality as well as quantity of potential practice learning opportunities.

\section{Practice Teachers}

Practice Teachers must develop their ability to identify students' learning needs and, where necessary, adapt their approach to meet these. This is particularly important as the demographics of the student population are changing. As the central figure within placement learning, it is the practice teacher's responsibility to ensure that the roles of manager, teacher, enabler and assessor are clearly understood and carried out appropriately. Practice teachers should recognise the potential impact of difference within the supervisory relationship. They must endeavour to practice in an anti-discriminatory manner, modelling a sound value base for their students.

\section{Health \& Social Services Trusts in Northern Ireland}

Health \& Social Services Trusts in Northern Ireland have a role in monitoring the quality of their placement learning opportunities. Practices teachers are often perceived as autonomous with limited systems for monitoring supervision or support. Trusts can no longer deny their responsibilities that include the setting of standards for practice teachers, on-site supervisors and placement sites. 
While both long arm and singleton practice teachers contribute to the provision of practice learning, the pressures of combining teaching with social work practice are well documented. It is essential that agencies and Trusts maintain and develop both long-arm and singleton placements. This will require support, training and workload planning.

Agencies should also consider forms of support that can be provided to students outside the supervisory relationship. This should include effective student support groups.

\section{Colleges}

Colleges have a key role in preparing students for placement. This is particularly relevant as younger and less experienced students join the new degree programmes. Course providers must consider how best to fulfil their role within the placement learning partnership, supporting both students and practice teachers. Planners \& Commissioners need to recognise and build upon the centrality of placement learning. Although resource limitations present very real difficulties, standards must be set to ensure that social work education prepares students for the diverse and complex responsibilities they might face.

\section{Future research}

At the outset it was recognised that this study involved only one perspective on a complex interpersonal process. There is much to be gained by replicating this study with tutors, on-site supervisors and practice teachers. Very few studies include the views of these key players on the supervision process. Evidence from the consultation process suggests that practice teachers are more willing to distinguish clearly between elements of supervision style. The comparison of the responses from all parties in a placement may be very illuminating.

Findings from this study have led to further hypotheses that should be tested. Some comments from students suggest that the content of supervision can differ significantly between practice teachers, with long-arm practice teachers focusing on learning, while singleton practice teachers focus more on case management. This study was not devised to consider this issue and there is insufficient data to prove or disprove the hypothesis. 
This survey's assessment of student learning was limited to a single question and this was by no means an objective measure. Other studies like Secker (1993) have used a longitudinal methodology analysing the content of structured interviews to assess the students' ability to apply theory to practice. A larger scale study incorporating data from the practice teacher, on-site supervisor, tutor and student would enable a better understanding of the causality in the relationship between student learning, supervision style and placement outcome.

\section{References}

Bridge, G. (1999) In defence of long-arm practice teaching. Journal of Practice Teaching in Health and Social Work, 2, 1, 7-19

Brown, A., and Bourne, I. (1996) The Social Work Supervisor. Buckingham: Open University Press

Collins, S., Ottley, G., and McMurran, M. (1992) Student and practice teacher perceptions of the enabling role in practice teaching. Social Work Education, $11,2,20-40$

Dick, E., Headrick, D., and Scott, M (2002) Practice Learning for Professional Skills: A review of literature. Report commissioned by the Scottish Executive as part of the reform of social work education in Scotland. Available at www. swap.ac.uk/Quality/SWreform/Scotland.asp

Doel, M., Shardlow, S., Sawdon, C., and Sawdon, D. (1996) Teaching Social Work Practice. Aldershot: Arena

Fernandez, E. (1998) Student perceptions of satisfaction with practicum learning. Social Work Education, 17, 2 173-201

Fortune, A.E., Feathers, C., Rook, S.R., Scrimenti, R.M., Smollen, P., Stemerman, B., and Tachu, E.L. (1985) Student satisfaction with field placement. Journal of Social Work Education, 21, 3, 92-104

Friedlander, M.L., and Ward, L.G. (1984) Development and validation of the supervisory styles inventory. Journal of Counseling Psychology, 31, 4, 541-557

Kadushin, A. (1976) Supervision in Social Work. New York: Columbia University Press

Karban, K. (1999) Long-arm practice teaching for the Diploma in Social Work: The views of students and practice teachers. Social Work Education, 18, 1, 59-70

54 Journal of Practice Teaching 6(1) 2005, pp.39-56 (C) 2005 Whiting and Birch 
DipSW students' satisfaction with practice teaching on their first placement

Knight, C. (1996) A study of MSW and BSW students' perceptions of their field instructors. Journal of Social Work Education, 32, 3 399-414

Lawson, H. (1998) Inside the long-arm model of practice teaching: The experiences of students, practice teachers and on-site supervisors' in practice teaching. in H. Lawson (Ed.) Changing Social Work. London: Jessica Kingsley

Marsh, P., and Tresiliotis, J. (1996) Ready to Practice? Social workers and probation officers: Their training and first year in work. Aldershot: Avebury

McVicker, H., and Bamford, D. (1999) Group approaches within social work education and training. Issues in Social Work Education, 19, 1, 35-54

Miller, M. (2002) Standardised clients: An innovative approach to practice learning. Social Work Education, 21, 6, 663-651

Moss, B. (1999) Reflections in the pool: An Evaluation of a long-arm practice teaching strategy for social work placements. Journal of Practice Teaching in Health and Scial Work, 2, 1, 35-53

Munson, C. (2002) Clinical Social Work Supervision. Binghampton, NY: Haworth

Raskin, M. (1982) Factors associated with student satisfaction in undergraduate social work field placements. Arete, 7, 1, 44-54

Rea, E. (1996) Practice teaching in Northern Ireland. Need for support for practice teachers. Child Care in Practice 3, 1

Rosenblatt, A., and Mayer, J.E. (1975) Objectionable supervisory styles: Student views. Social Casework, 59, 3, 131-137

Scottish Executive (2003) Reform of Social Work Education: Proposals for consultation on the curriculum for the new honours degree. Available at $h t t p: / / w w w$. scotland.gov.uk/library5/social/rswe-05.asp

Secker, J. (1993) From Theory to Practice in Social Work. Aldershot: Avebury

Shafer, C.M. (1982) The methods of field instruction. in B.W. Sheafor and L.E. Jenkins Quality Field Instruction in Social Work. New York: Longman

Short, Glenda F Lester (2002) Learning, Teaching, and Supervisory Styles in Field Education: The working alliance investigated Unpublished Dissertation. University of South Carolina

Stokes, Idris (1996) Black practice teachers: A review of some literature and its meaning for social work education and practice. Social Work Education, 15,2

Stoltenberg, C.D. and Delworth, U. (1987) Supervising Counselors and Therapists. San Francisco: Josey Bass

Valios, N. (2002) A degree of flexibility. Community Care, 9th May, pp.24-25

55 Journal of Practice Teaching 6(1) 2005, pp.39-56

(C) 2005 Whiting and Birch 
Vonk, M. Zucrow, E.E., and Thyer, B. (1996) Field MSW students' satisfaction with practicum supervision: The effect of supervisor gender. Journal of Social Work Education, 32, 3, 415-420

Wilson, G. (2001) Developing practice learning: The practice teacher's perspective in social work and innovation. in An Anthology of Advanced Level Practice. Belfast: CCETSW, Northern Ireland 